Plant Tissue Cult. \& Biotech. 23(2): 263-273, 2013 (December)

$\overline{\text { PTC\&B }}$

\title{
Cloning of the Plasma Membrane Sodium/Hydrogen Antiporter SOS1 for its Over expression in Rice
}

\author{
Samsad Razzaque, Sabrina M. Elias, Sudip Biswas, Taslima \\ Haque and Zeba I. Seraj*
}

Plant Biotechnology Lab., Department of Biochemistry and Molecular Biology, University of Dhaka, Dhaka-1000, Bangladesh

Key words: Antiporter, SOS1, Cloning, Plasma membrane, Overexpression

\begin{abstract}
Soil salinity adversely affects plant growth, development and disturbs intracellular ion homeostasis which results in cellular toxicity. The salt overly sensitive 1 (SOS1) gene is a critical component of salt tolerance in many species and encodes a plasma membrane $\mathrm{Na}^{+} / \mathrm{H}^{+}$antiporter that plays an important role in germination and growth in saline environments. In the current study, the coding sequence of SOS1 gene (3447 bp) was amplified from a Bangladeshi rice landrace, Pokkali, by applying the fusion PCR strategy. SOS1 PCR amplicons were firstly cloned into $\mathrm{pENTR/D-TOPO}$ and then recombined with the binary vector, $\mathrm{pH} 7 \mathrm{WG} 2$, through LR reaction. Positive colonies were validated by PCR, restriction digestion and sequencing. Finally, the constructed vector was transformed into Agrobacterium tumeficiens, LBA4404 strain, to initiate Agrobacterium-mediated transformation with the provision to transfer the cloned SOS1 into farmer popular rice varieties.
\end{abstract}

\section{Introduction}

Soil salinity has been a major threat in crop production worldwide and it exists approximately in $20 \%$ of world's cultivable lands (Rhoades and Loveday 1990, Qadir et al. 2008). Approximately 2 million ha of lands are being annually affected by salinity (Kalaji and Pietkiewica 1993). High salt concentrations cause hyperosmotic stress and ion imbalance in plants which often leads to oxidative damage in cellular components as a secondary effect (Qadir et al. 2008). In Bangladesh the increased pressure of a growing population has resulted in the demand for more food production. Hence it is important to explore the possibilities of producing crops such as rice in hitherto fallow lands in the coastal south region affected by salinity to maximize food production.

*Author for correspondence: <zebai@univdhaka.edu>. 
Many attempts have been made to improve crop productivity by conventional breeding as well as genetic transformation for abiotic stress tolerance, like salinity (Mittler and Blumwald 2010, Reguera et al. 2012, Verma et al. 2007, Tuteja et al. 2012). However, it has been very difficult to combine tolerance with high yield. Transgenic approaches are more likely to be successful in maintaining yields, while improving tolerance such as to salinity, particularly if high yielding cultivars are transformed using stress-inducible promoters (Wang et al. 2013). There are also quite a few clear examples where single genes have significantly increased yield, particularly to drive domestication (to control tiller number, branching, and seed number) and that domestication of an important crop can lead to green revolution (Tester and Langridge 2010).

SOS1 is one of the many potential candidate genes for conferring salt tolerance. The coding sequences of SOS1 gene in rice is about 3447 nucleotide bases long and predicted to encode a $127-\mathrm{kDa}$ protein with 12 transmembrane domains in the N-terminal part (Shi et al. 2000). In addition, the expression of SOS1 is pervasive, but stronger in the epidermal cells surrounding the root-tip, with parenchyma cells neighboring the xylem. SOS1 acts as a $\mathrm{Na}^{+} / \mathrm{H}^{+}$antiporter on the plasma membrane and plays a vital role in sodium efflux from root cells and the long distance $\mathrm{Na}^{+}$transport from root to shoot (Shi et al. 2002). In the current study, SOS1 has been cloned from a salt tolerant rice landrace Pokkali, with the aim to transform it into farmer popular BRRI varieties for enhancing the salinity tolerance of the latter.

\section{Materials and Methods}

Rice landrace Pokkali was grown for 15 days and $150 \mathrm{mM}$ salt stress was applied to extract total RNA using TRIZOL (Invitrogen) method. The extracted RNA was quantified using Nanodrop ${ }^{\circledR}$ spectrophotometer ND-1000 (Thermo Fisher Scientific inc.), and the cDNA was synthesized from isolated RNA by using SuperScript ${ }^{\mathrm{TM}}$ first-strand synthesis system (Invitrogen). The amplification of SOS1 coding region was accomplished applying fusion PCR/overlap PCR strategy. Primers were designed accordingly to attain the task (Fig. 1)

The first fragment was amplified by PCR with the SOS1 forward primer (SOS1_F) and SOS1 overlap reverse primer (SOS1_OL_R) (Table 1). PCR reaction program for amplifying the first fragment was optimized as follows. Initial denaturation at $95^{\circ} \mathrm{C}$ for $5 \mathrm{~min}$ and 35 cycles of denaturation at $95^{\circ} \mathrm{C}$ for $1 \mathrm{~min}$, annealing at $61.5^{\circ} \mathrm{C}$ for $1 \mathrm{~min}$, extension at $72^{\circ} \mathrm{C}$ for $2.10 \mathrm{~min}$ followed by a final extension at $72^{\circ} \mathrm{C}$ for $10 \mathrm{~min}$. A final concentration of $2.3 \mathrm{mM} \mathrm{MgCl}, 0.1 \mathrm{mM}$ dNTPs, $0.3 \mu \mathrm{M}$ of each primer and 1 unit of recombinant Taq polymerase (Invitrogen, Carlsbad, CA, USA) was used. The forward primer was designed 
adding CACC overhang to ensure compatibility with $\mathrm{pENTR/D-TOPO}$ vector (Fig. 2A).

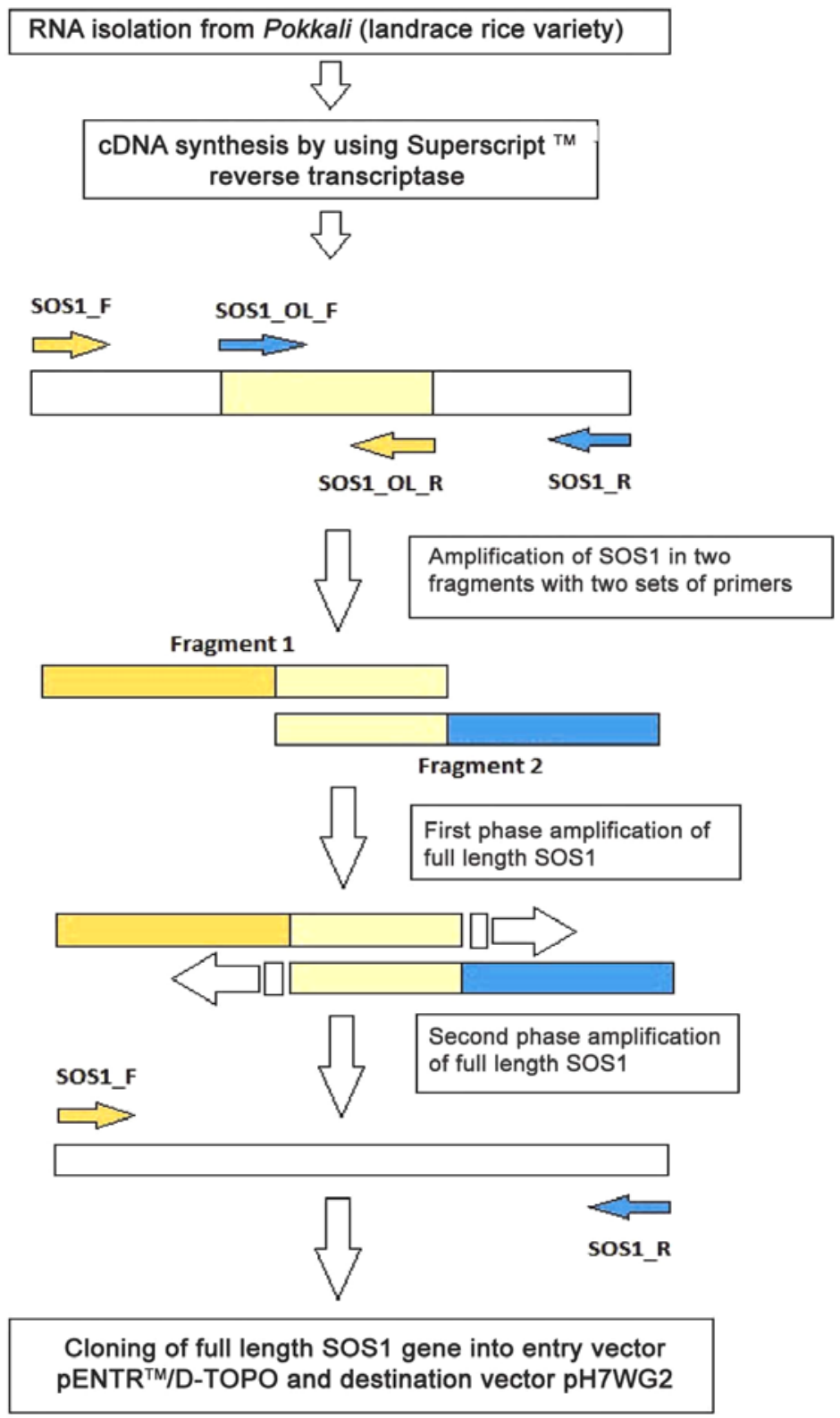

Fig.1. Schematic presentation of SOS1 cloning method

The second fragment of SOS1 (1.7 kbp) was then amplified with designed overlap forward primer (SOS1_OL_F) and SOS1 reverse primer (SOS1_R) (Table 1). PCR conditions were optimized with initial denaturation at $95^{\circ} \mathrm{C}$ for $5 \mathrm{~min}$ 
and 35 cycles of denaturation at $95^{\circ} \mathrm{C}$ for $1 \mathrm{~min}$, annealing at $59.5^{\circ} \mathrm{C}$ for $1 \mathrm{~min}$, extension at $72^{\circ} \mathrm{C}$ for $2.10 \mathrm{~min}$ and final extension at $72^{\circ} \mathrm{C}$ for $10 \mathrm{~min}$ with final concentration of $2.3 \mathrm{mM} \mathrm{MgCl}_{2}, 0.1 \mathrm{mM}$ dNTPs and $0.3 \mu \mathrm{M}$ of each primer and 1 unit of recombinant Taq polymerase (Invitrogen, Carlsbad, CA, USA).

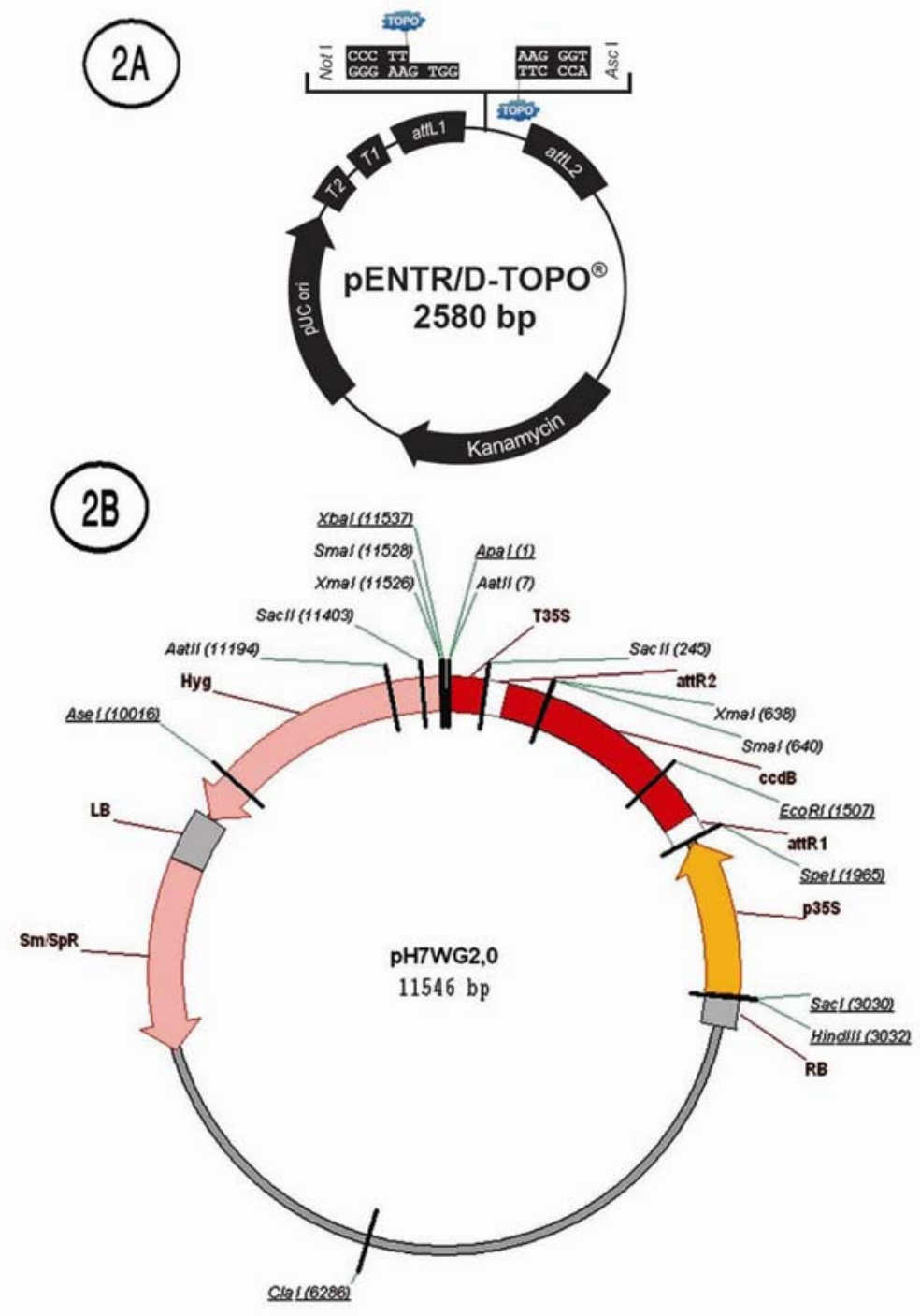

Fig. 2. Vectors used in this method. A. Entry vector pENTR/D TOPO. B. Destination vector pH7WG2.0.

After amplifying two fragments of SOS1 gene, the desired fragments were gel purified using Qiaquick Gel extraction kit (Qiagen) and then fusion PCR/overlap PCR technique was initiated to amplify the whole fragment of SOS1 gene in a two phase PCR program. At the first Phase, PCR reactions were carried 
out with amplified Fragments 1 and 2 of SOS1 without any primer. PCR conditions were, initial denaturation at $95^{\circ} \mathrm{C}$ for $5 \mathrm{~min}$ and 15 cycles of denaturation at $95^{\circ} \mathrm{C}$ for $1 \mathrm{~min}$, annealing at $65^{\circ} \mathrm{C}$ for $1.30 \mathrm{~min}$, extension at $72^{\circ} \mathrm{C}$ for $2.10 \mathrm{~min}$ with a final concentration of $2.4 \mathrm{mM} \mathrm{MgCl}_{2}, 0.24 \mathrm{mM} \mathrm{dNTPs}$ and 1 unit of recombinant Taq polymerase (Invitrogen, Carlsbad, CA, USA). At the second phase, PCR reactions were carried out adding $0.3 \mu \mathrm{M}$ of SOS1_F and SOS1_R primers, $1.2 \mathrm{mM} \mathrm{MgCl} 2,0.16 \mathrm{mM}$ dNTPs and 1 unit of recombinant Taq polymerase with pfx (Proof reading enzymes) (Invitrogen, Carlsbad, CA, USA) with the product of first phase PCR reaction. PCR condition was set as follows; an initial denaturation at $95^{\circ} \mathrm{C}$ for $5 \mathrm{~min}$ and 20 cycles of denaturation at $95^{\circ} \mathrm{C}$ for $1 \mathrm{~min}$, annealing at $65^{\circ} \mathrm{C}$ for $1.30 \mathrm{~min}$, extension at $72^{\circ} \mathrm{C}$ for $2.10 \mathrm{~min}$ with a final extension at $72^{\circ} \mathrm{C}$ for $30 \mathrm{~min}$.

Final PCR amplicons were gel extracted and quantified through nanodrop. Cloning reaction into $\mathrm{pENTR/D-TOPO}$ vector (Invitrogen) was then initiated following manufacturer's protocol (Publication part number 25-0434, Invitrogen). The pENTR_SOS1 plasmid construct was transformed into E. coli DH5 $\alpha$ competent cells through heat shock using standard protocols (Sambrook et al. 1989). Successful cloning was then confirmed by PCR of pENTR_SOS1 plasmid, restriction digestion of the isolated plasmid with BamHI and EcoRV restriction enzymes (NEBr inc) individually followed by a final confirmation by direct sequencing of the vector and gene specific primers.

Successful pENTR/D-TOPO cloning allowed recombining the desired sequence of SOS1 into a destination vector by using the Gateway ${ }^{\circledR}$ LR recombination reaction (invitrogen) (Fig $2 \mathrm{~B}$ ). The LR reaction was carried out following the manufacturer's protocol. Positive colonies were screened out by gene specific primers and restriction digestions. Restriction endonuclease NdeI (NEBr inc.) was used and confirmation was carried out by comparing the transformed plasmid with non-transformed plasmid.

Table1. List of primers used in the study and corresponding sequences.

\begin{tabular}{ll}
\hline Primer Name & Sequence \\
\hline SOS1_F & 5'-CACCATGGACAATCCCGAGGCGGA-3' \\
SOS1_OL_R & 5'-GTGGCAACCTGCTCATTTGAAGGAAC--3' \\
SOS1_OL_F & 5'-GTTCCTTCAATGAGCAGCGTTGCCAC-3' \\
SOS1_R & 5'-TCATCGATCAGCAGCGCTGGAG-3' \\
\hline
\end{tabular}

Finally, Agrobacterium tumefaciens (LBA4404) was electroporated with the constructed pH7WG2_ SOS1 using standard protocols (Sambrook et al. 1989). Positive colonies were authenticated by PCR reactions with gene specific primers (Table 1). 


\section{Results and Discussion}

A single PCR program was not successful to amplify the whole sequence due to the large coding sequence (CDS) of SOS1 gene (3447 bp). Hence fusion PCR strategy was adapted for amplifying the whole CDS of SOS1 gene which is specifically useful for amplification of genes that are large in sequence length. In the current experiment primers were designed strategically (Fig. 1) from the available rice genome sequence to amplify two fragments of the SOS1 gene that overlaps each other in a common sequence region. The first fragment $(1.735 \mathrm{kbp})$ and second fragment $(1.725 \mathrm{kbp})$ were successfully amplified (Fig. 3A) in two different PCR events. In a separate two phase PCR event the two fragments could be overlapped followed by amplification of the whole $3447 \mathrm{bp}$ CDS (Fig. 3B).
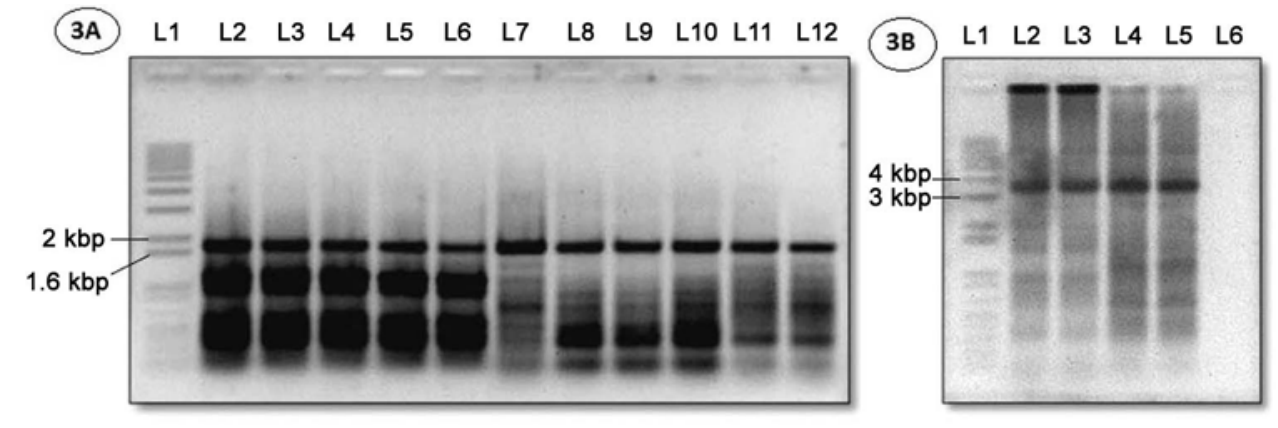

Fig. 3A-B: A. PCR amplification of two fragments of the SOS1 gene; L1: $1 \mathrm{~Kb}^{+}$ladder, L2L6: First fragment of SOS1 (1.7 kbp), L7-L12: Second fragment of SOS1 gene (1.7 kbp). B. PCR amplification of full length SOS1 gene; L1: $1 \mathrm{~Kb}^{+}$ladder, L2-L5: full length of SOS1 gene (3.4kb).

The amplified product of SOS1 gene was cloned in the pENTR/D-TOPO cloning vector which is designed to facilitate rapid, directional TOPO ${ }^{\circ}$ cloning of blunt-end PCR products for entry into the Gateway ${ }^{\circledR}$ System. The system was adopted for this experiment since inserts can be cloned in the vector in correct orientation with efficiencies equal to or greater than $90 \%$ (Publication part number 25-0434, Invitrogen). Following cloning and transformation and after $\mathrm{O} / \mathrm{N}$ incubation, colonies were observed on the LB plate containing the antibiotic kanamycin. Confirmation of the successful cloning was observed after isolation of correct size plasmid (Fig. 4A) from the colonies and PCR amplification with the full length SOS1 primers. Only two cloned plasmids showed the expected 3.4 kbp (Fig. 4B).

The clone was further confirmed by restriction digestion of the pENTR_SOS1 plasmid with BamHI (Single cut) and EcoRV (Double cut). By 
digestion with BamHI, the expected product size of positive pENTR_SOS1 was 6 $\mathrm{kb}$ and by digestion with EcoRV, the expected products sizes of positive pENTR_SOS1 were 5.4 and $0.6 \mathrm{~kb}$. Only one clone showed desired product size bands by digestion with BamHI and EcoRV individually (Fig. 4C). Further confirmation of the SOS1 cloning into pENTR was performed by sequencing using gene-specific and M13 primer pairs. (Fig. 5)

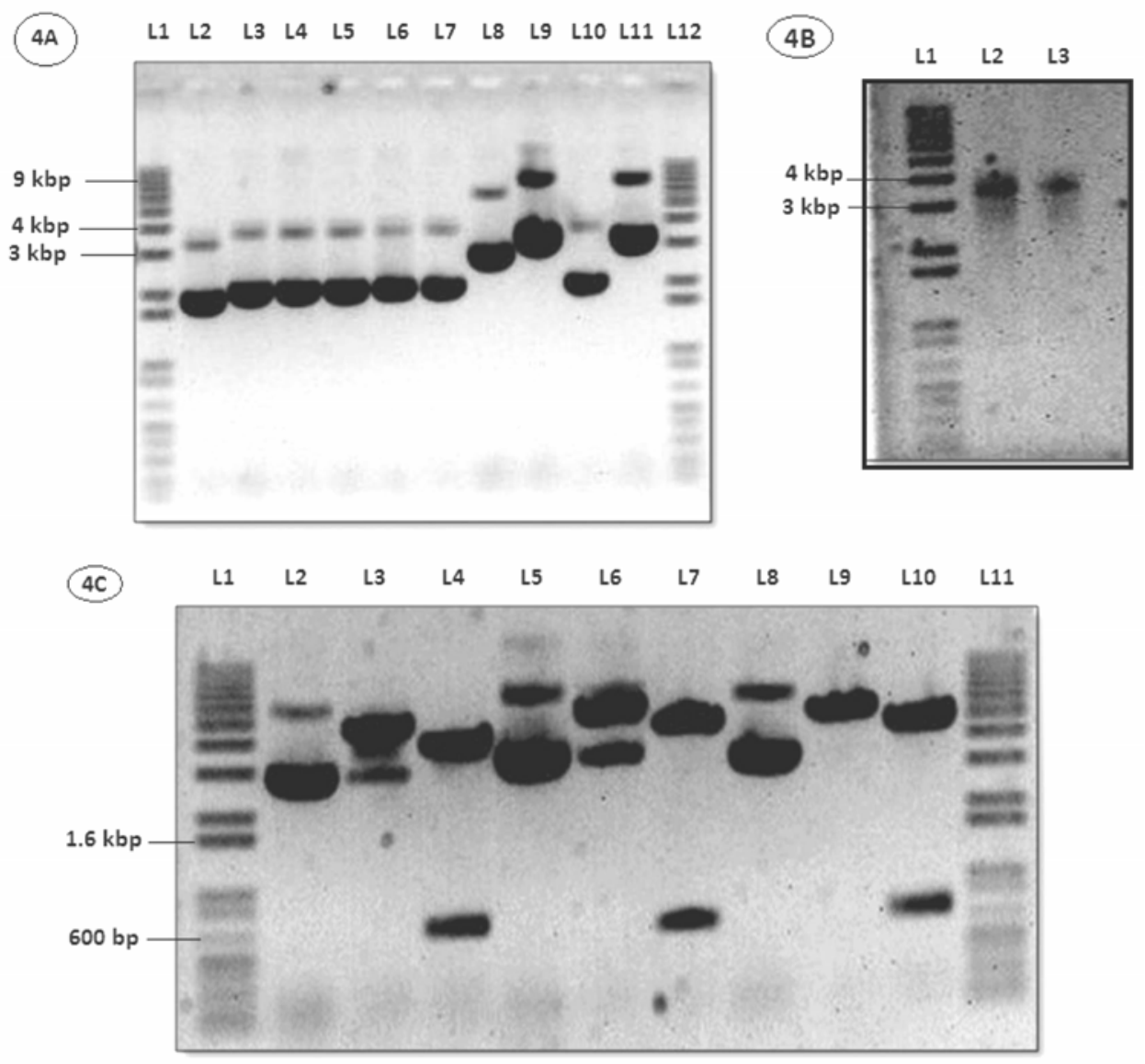

Fig. 4A-C: A. Plasmid was isolated from SOS1_pENTR cloning; L1 and L12: 1 kb + DNA ladder, L2L11: plasmid that was isolated from colonies. Only L9 and L11- were the right size (Supercoiled plasmid band came to the $3.4 \mathrm{kbp}$ size) and positive. B. PCR amplification of full length SOS1 gene from cloned plasmid (pENTR_SOS1); L1-1 kb+ DNA ladder, L2-L3: whole insert of SOS1 gene $(3.4 \mathrm{~kb})$. C. Restriction digestion (RD) of cloned plasmid (pENTR_SOS1) with BamHI (Single cut) and EcoRV (Double cut); L1: $1 \mathrm{~Kb}+$ ladder, L2, L5, L8: Uncut plasmid, L3, L6, L9: Cut with BamHI (Expected size 6Kb); L4, L7, L10: Cut with EcoRV (Expected size 5.4 and $0.6 \mathrm{~kb}$ ); L8positive with true single and double cut. 


\begin{tabular}{|c|c|c|c|c|c|c|}
\hline \multicolumn{4}{|c|}{ Range 1: 6 to 3452 GenBank Graphics } & \multirow{2}{*}{$\begin{array}{l}\text { V Next Match } \\
\text { Gaps } \\
0 / 3447(0 \%)\end{array}$} & \multirow{2}{*}{\multicolumn{2}{|c|}{$\begin{array}{l}\text { A Previous Match } \\
\text { Strand } \\
\text { Plus/Plus } \\
\end{array}$}} \\
\hline $\begin{array}{l}\text { Score } \\
6366 \\
\end{array}$ & bits(3447 & $\begin{array}{ll} & \text { Expect } \\
\text { 7) } & 0.0 \\
\end{array}$ & $\begin{array}{l}\text { Identities } \\
3447 / 3447(100 \%)\end{array}$ & & & \\
\hline Query & A: & \multirow{2}{*}{\multicolumn{4}{|c|}{ 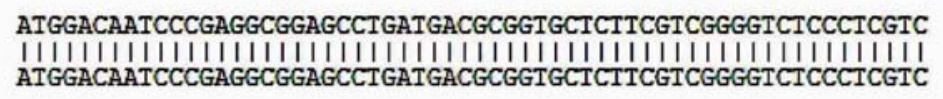 }} & 60 \\
\hline Sbjet & $A^{-}$ & & & & & 65 \\
\hline Query & 61 & \multirow{2}{*}{\multicolumn{4}{|c|}{ 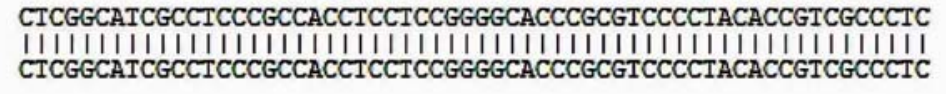 }} & 120 \\
\hline Sbjct & 66 & & & & & 125 \\
\hline Query & 121 & \multirow{2}{*}{\multicolumn{4}{|c|}{$\begin{array}{l}\text { CICGTCCTCGGCGTCGCCCTCGGATCGCTCGAATTIGGCACAAAACATGGCATGGGCAAA } \\
|||||||||||||||||||||||||||||||||||||||||||||||||||||||||||||| \\
\text { CICGTCCTCGGCGTCGCCCICGGATCGCICGAATTIGGCACAAACATGGCATGGGCAAA }\end{array}$}} & 180 \\
\hline Sbjet & 126 & & & & & 185 \\
\hline Query & 181 & \multirow{2}{*}{\multicolumn{4}{|c|}{ 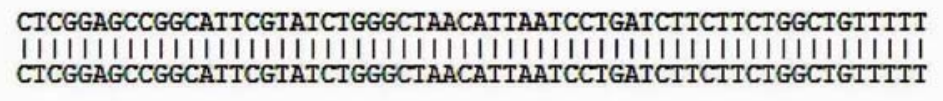 }} & 240 \\
\hline Sbjet & 186 & & & & & 245 \\
\hline Query & 241 & \multirow{2}{*}{\multicolumn{4}{|c|}{ 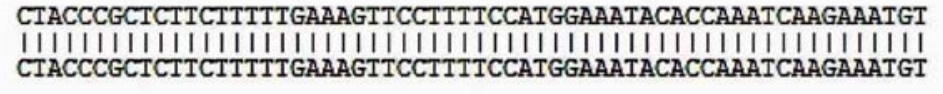 }} & 300 \\
\hline Sbjct & 246 & & & & & 305 \\
\hline Query & 301 & \multirow{2}{*}{\multicolumn{4}{|c|}{ 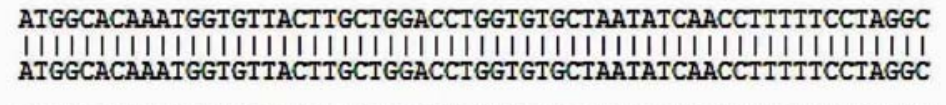 }} & 360 \\
\hline Sbjct & 306 & & & & & 365 \\
\hline Query & 361 & \multirow{2}{*}{\multicolumn{4}{|c|}{ 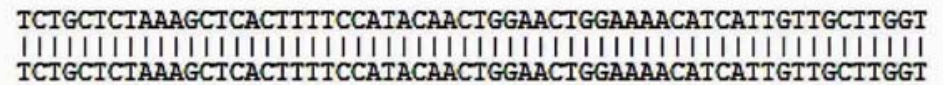 }} & 420 \\
\hline Sbjct & 366 & & & & & 425 \\
\hline
\end{tabular}

Fig.5. Sequence alignments showing similarity of sequenced SOS1 insert in the cloning reaction with the SOS1 reference sequence available from japonica rice genome sequence consortium. Here query refers to the cloned SOS1 sequence and subject refers to the reference sequence.

The SOS1 cDNA was transferred into the gateway destination vector pH7WG2.0 (Karimi et al. 2002) from the entry clone pENTR_SOS1 by LR recombination reaction. This recombination reaction creates an expression clone for plant transformation and contains the selectable marker for transformation into bacteria and plants and is a compatible vector for Agrobacterium. Following LR recombination reaction and transformation on the next day, colonies were observed on the LB plate containing the antibiotic spectinomycin/streptomycin. Plasmids were isolated from these colonies (Fig. 6A) and positive clones were confirmed by PCR using insert specific primers (Fig. 6B) and restriction digestion by NdeI enzyme (Fig. 6C). The enzyme has three cutting sites in the plasmid but the positive one with SOS1 gene could easily be identified due to size variations.

The constructed destination vector was transformed into LBA4404 strain of Agrobacterium by electroporation. The transformed plate was kept at $28^{\circ} \mathrm{C}$ for 72 hrs and positive colonies were screened out by PCR with insert specific primers (Table 1). The PCR reaction was conducted to amplify the whole region of SOS1 gene (3.447 kbp) with high fidelity Taq polymerase (Invitrogen). The insert was 
amplified to the expected size (Fig. 7). The final destination vector (Fig. 8) was then used to do Agrobacterium mediated transformation.

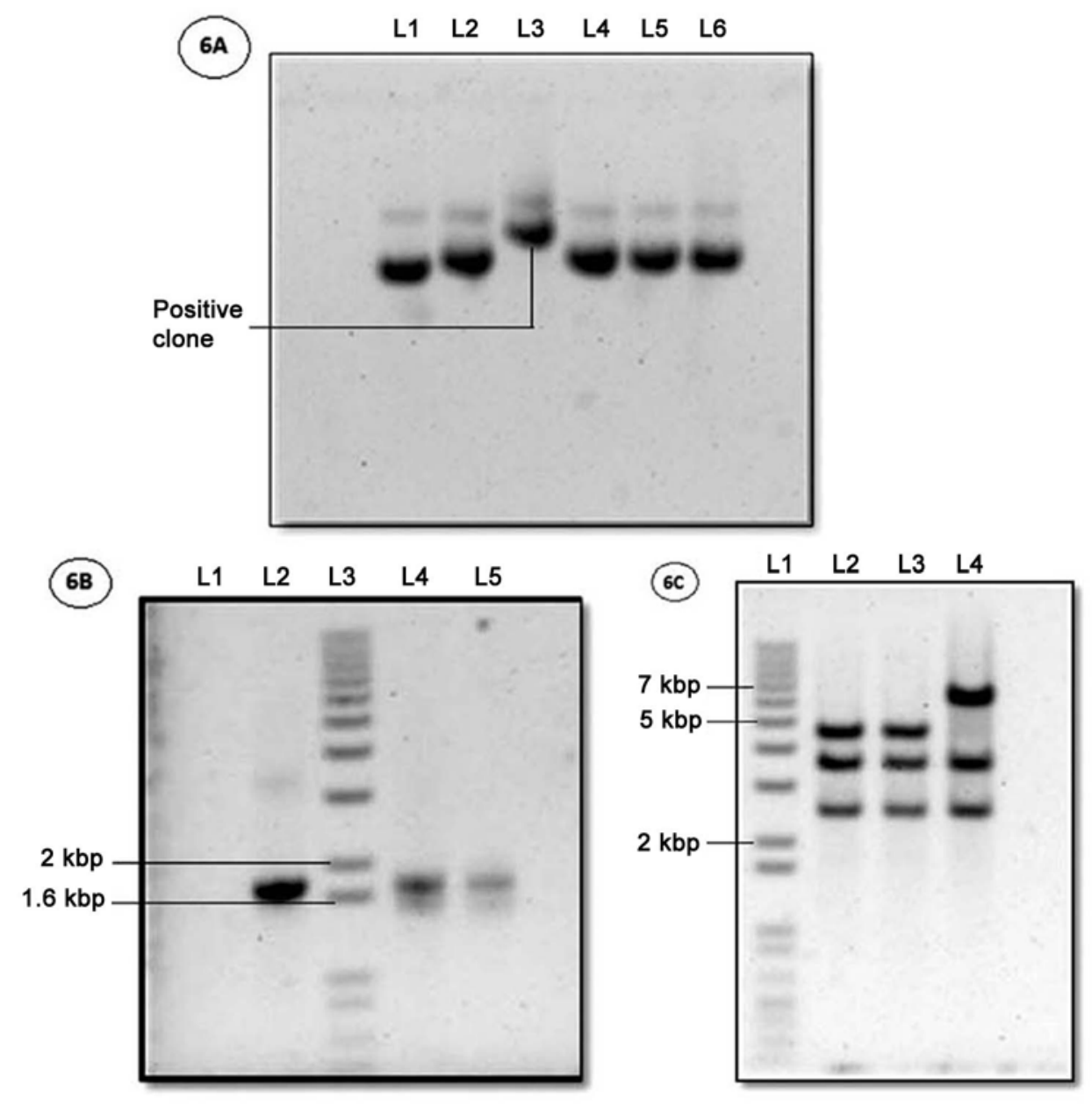

Fig. 6A-C: A. Isolated plasmid after LR recombination reaction; L1: Isolated destination vector, pH7WG2 plasmid without SOS1, L2- L6: Isolated plasmid after LR, L3 came up as a positive one. B. PCR confirmation of positive pH7WG2_SOS1 clones; L1: Negative control, L2: Positive Control, L3: $1 \mathrm{~Kb}+$ DNA ladder, L4-L5-positive bands $(1.7 \mathrm{kbp})$. C. LR was further confirmed by restriction digestion of the PH7WG2.0_SOS1 construct with the restriction enzymes Nde1 L1: $1 \mathrm{~kb}+$ DNA ladder, L2-L3: Plasmid without SOS1, L4- is the correct plasmid with the SOS1 gene (Expected band size was $7,3.7$ and $2.6 \mathrm{~kb}$ ).

The challenge in cloning the SOS1 CDS was its sequence length. Amplification of the full $3.4 \mathrm{~kb}$ with high fidelity Taq polymerases specific for larger fragments was not considered since it amplifies the insert with a mixture of both blunt and A ends (Platinum ${ }^{\circledR}$ Taq DNA polymerase high fidelity protocol, Invitrogen). pENTR/D-TOPO cloning kit only allows insertion of the 


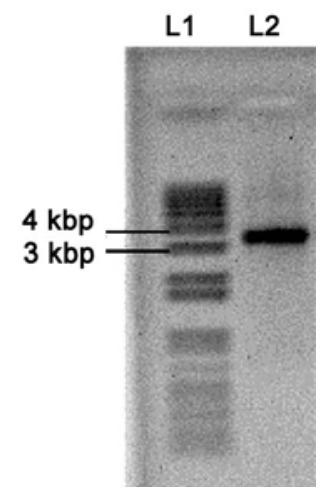

Fig.7. PCR confirmation after isolating plasmid from Agrobacterium. L1: 1Kb + DNA ladder. L2-PCR product of the insert with size $3.4 \mathrm{~kb}$.

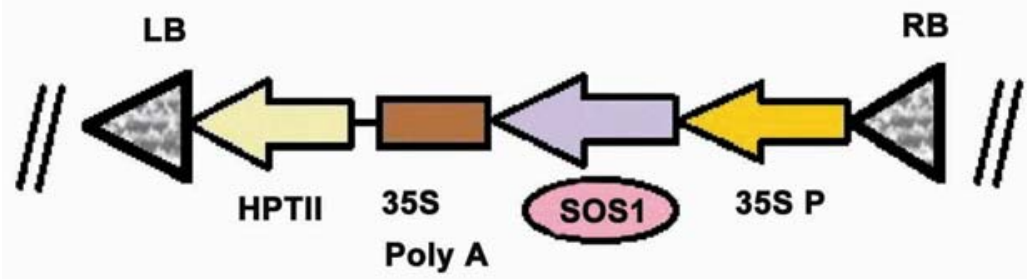

Fig. 8. T-DNA border of pH7WG2_SOS1.

Blunt end products, but high fidelity Taq polymerase adds a single deoxyadenosine (A) to the 3 ' ends of PCR products which make the amplified product incompatible to clone into pENTR/D-TOPO vector. Hence the overlapping fusion PCR strategy needed to be adopted which could successfully accomplish the task. Moreover the gene length was larger than the insert size recommended for cloning in pENTR-D-TOPO vector (Invitrogen). Modification in the incubation time and volume of the reaction during cloning could successfully overcome the insert size restriction; though the efficiency rate was drastically reduced as observed by the low number of positive colonies. Successful cloning was accomplished by initiating some major changes in the manufacturer's protocol. The incubation period was extended to an overnight period and reaction volume was maintained to 10 instead of 6 microlitre. Combination of the strategies adapted in the experiment can be beneficial in other studies where large sequence length of the gene is a limiting factor in cloning.

\section{Acknowledgement}

The authors would like to thank BAS-USDA PALS program for funding the project. 


\section{References}

Kalaji MH and S Pietkiewica (1993) Salinity effects on plant growth and other physiological processes. Acta Physiol. Plantarum 15: 89-124.

Karimi M, D Inze and A Depicker (2002) GATEWAY vectors for Agrobacteriummediated plant transformation. Trends Plant Sci. 7(5): 193-195.

Mittler R and E Blumwald (2010) Genetic engineering for modern agriculture: challenges and perspectives. Ann. Rev. Plant Biol. 61: 443-462.

Qadir M, A Tubeileh, J Akhtar, A Larbi, PS Minhas and MA Khan (2008) Productivity enhancement of salt-affected environments through crop diversification. Land Degradation Develop. 19: 429-453.

Reguera M, Z Peleg and E Blumwald (2012) Targeting metabolic pathways for genetic engineering abiotic stress-tolerance in crops. Biochim. Biophys Acta. 1819(2): 186-194.

Rhoades JD and J Loveday (1990) Salinity in irrigated agriculture. In: American Society of Civil Engineers, Irrigation of Agricultural Crops (Monograph 30) (Steward, B.A. and Nielsen, D.R.,eds), . American Society of Agronomists: 1089-1142.

Sambrook J, EF Fritsch and T Maniatis (1989) Molecular cloning: A laboratory manual, Cold Spring, Harbor Laboratory Press.

Shi H, M Ishitani, C Kim and JK Zhu (2000) The Arabidopsis thaliana salt tolerance gene SOS1 encodes a putative $\mathrm{Na}^{+} / \mathrm{H}^{+}$antiporter. Proc. Natl. Acad. Sci. USA 97(12): 68966901.

Shi H, FJ Quintero, JM Pardo and JK Zhu (2002) The putative plasma membrane $\mathrm{Na}(+) / \mathrm{H}(+)$ antiporter SOS1 controls long-distance $\mathrm{Na}(+)$ transport in plants. Plant Cell 14(2): 465-477.

Tester $\mathbf{M}$ and $\mathbf{P}$ Langridge (2010) Breeding technologies to increase crop production in a changing world. Science 327(5967): 818-822.

Tuteja N, S Verma, RK Sahoo, S Raveendar and IN Reddy (2012) Recent advances in development of marker-free transgenic plants: regulation and biosafety concern. J Biosci. 37(1): 167-197.

Verma D, SL Singla-Pareek, D Rajagopal, MK Reddy and SK Sopory (2007) Functional validation of a novel isoform of $\mathrm{Na}^{+} / \mathrm{H}^{+}$antiporter from Pennisetum glaucum for enhancing salinity tolerance in rice. J. Biosci. 32(3): 621-628.

Wang JY, LD Lai, SM Tong and QL Li (2013) Constitutive and salt-inducible expression of SIBADH gene in transgenic tomato (Solanum lycopersicum L. cv. Micro-Tom) enhances salt tolerance. Biochem. Biophys Res. Commun. 432(2): 262-267. 